\title{
ATUAÇÃO DO BANCO NACIONAL DE DESENVOLVIMENTO ECONÔMICO E SOCIAL NO PADRÃO DE FINANCIAMENTO DO II PLANO NACIONAL DE DESENVOLVIMENTO: 1974/1979
}

\author{
João Paulo Reco de Oliveira \\ Graduado em Ciências Econômicas pela Universidade Federal de Santa Catarina (UFSC) \\ Endereço para contato: Rua José de Paula, 1022 - Chácara de Ouro - Mogi Guaçu - SP \\ CEP: 13840-050 - E-mail: joaopauloreco@ hotmail.com
}

\begin{abstract}
André da Silva Redivo
Doutorando em Economia do Desenvolvimento da Universidade Federal do Rio Grande do Sul (UFRGS). Endereço para contato: Rua Barão do Triunfo, 1048 - Santana do Livramento - RS

CEP: 97573-634 - E-mail: andre.redivo@gmail.com

\section{Silvio Antônio Ferraz Cário}

Professor Associada II da Universidade Federal de Santa Catarina (UFSC)

Endereço para contato: Rua Lauro Linhares, 897 - Bairro Trindade - Florianópolis - SC

CEP: 88036-001 - E-mail: fecario@yahoo.com.br
\end{abstract}

Recebido em 17 de agosto de 2015. Aceito em 12 de agosto de 2015.

\begin{abstract}
Resumo
Em 1974, Ernesto Geisel assumiu a Presidência da República do Brasil com o propósito de manter as taxas de crescimento econômico elevadas dos anos anteriores, a despeito de um contexto econômico internacional conturbado. Para tanto, elaborou nova estratégia de desenvolvimento de longo prazo expressa no II Plano Nacional de Desenvolvimento (II PND). O plano tinha como objetivo central superar pontos de estrangulamento da economia brasileira, realizando investimentos nos setores de bens intermediários e de capital e na área de infraestrutura. Para a realização deste bloco de investimentos, o padrão de financiamento contou, dentre outras fontes, com o Banco Nacional de Desenvolvimento Econômico e Social (BNDES). Os resultados apontaram que, no propósito de financiar os projetos de investimentos, esta instituição não só criou como elevou o valor das fontes de recursos. Assim como, os dados analisados apontaram para atuação efetiva e primordial da instituição financeira para a realização e a conclusão de parte dos objetivos do II PND.
\end{abstract}

\section{Palavras-chave}

BNDES. II PND. Financiamento do Desenvolvimento.

\begin{abstract}
In 1974, Ernesto Geisel took over the Presidency of Brazil in order to maintain high economic growth rates of previous years, despite an international economic context troubled. To this end, developed new long-term development strategy expressed in the II National Development Plan (II PND). The plan had as its main objective to overcome bottlenecks in the Brazilian economy, making investments in the sectors of intermediate goods and capital and in infrastructure. To carry out this investment block, the pattern of financing included, among other sources, with the National Bank for Economic and Social Development (BNDES). The results showed that the purpose of financing investment projects, this institution not only created as increasing the value of sources of funds. As well as analyzed,
\end{abstract}


the data pointed to effective and essential role of this financial institution for the achievement and completion of part of the objectives of the II PND.

\section{Key-words}

BNDES. II PND. Development Finance.

\section{INTRODUÇÃO}

O governo brasileiro, sob a Presidência da República de Ernesto Geisel, lançou em 1974, o II Plano Nacional de Desenvolvimento Econômico - 1974 - 1979 (II PND) com o propósito de promover transformações estruturais na economia. Tratava-se de um ambicioso plano de governo, com a forte atuação do Estado, tendo como principais objetivos: consolidar uma sociedade industrial moderna e um modelo de economia competitiva; concentrar esforços na política de energia; fortalecimento da política científica e tecnológica; esforço na área de integração nacional; criar estratégias de desenvolvimento social; e fomentar a integração com a economia mundial (II PND, 1975).

Segundo Velloso (1986), o Plano apresentou significativo grau de planejamento, a institucionalidade construída é um exemplo desta concepção. Sendo assim, as metas estavam estabelecidas e as bases institucionais alicerçadas, portanto, bastava definir seu padrão de financiamento. $\mathrm{O}$ governo brasileiro definiu que a empresa pública seria financiada através de empréstimos externos, dado a nova "janela de liquidez" existente no cenário mundial. Do ponto de vista do financiamento interno, o Banco Nacional de Desenvolvimento Econômico e Social (BNDES) ${ }^{1}$ foi capacitado para assumir esse importante papel para o desenvolvimento econômico e industrial, fornecendo linhas de crédito de longo prazo para a empresa privada nacional.

A responsabilidade de principal agente financeiro interno do II PND insere-se no propósito de criação deste Banco em 1952, instituído com a função de solucionar problemas de mobilização e gestão de recursos advindos da Comissão Mista Brasil - Estados Unidos (CMBEU). Suas atividades iniciais eram voltadas para a infraestrutura e seus recursos disponibilizados quase que exclusivamente para o setor público. Ainda que tenha se alterado esta exclusividade, em favor do setor privado, a partir de 1964, o propósito de constituir um banco financiador de base estrutural da economia se manteve, dado que o II PND se voltava para a realização de investimentos fortes em insumos básicos, bens de capital e segmentos infraestruturais, como energia e transportes.

No intuito de exercer o papel que lhe foi dado, o Banco criou seu $1^{\circ}$ Plano Quinquenal de Ação. As diretrizes desse documento caminharam de encontro com os objetivos traçados no II PND. O governo brasileiro, por sua vez, capacitou sua fonte de recursos, transferindo as arrecadações do Programa de Integração Social (PIS) e do Programa de Formação do Patrimônio do Servidor Público (PASEP) para seu passivo. Além disso, foram criadas três subsidiárias que tinham o objetivo principal de capitalizar empresas nacionais. Essas novas empresas, somadas à já existente Agência Especial de Financiamento Industrial (FINAME) e o próprio Banco, formariam o Sistema BNDES.

\footnotetext{
${ }^{1}$ Criado inicialmente com o nome de BNDE, o "S" de social só foi incluindo em 1982, para tanto, neste trabalho será utilizado o nome do Banco hoje, isto é, BNDES.
} 
No âmbito acadêmico, muitas teses, dissertações e livros foram escritos sobre o período de vigência do II PND, sendo destaques: a visão contrária de sua ocorrência expressa no trabalho desenvolvido por Lessa (1988), cujo teor demonstrou vida curta ao projeto levando a perseguir trajetória do sonho ao fracasso; a visão favorável escrita por Castro e Souza (1985) cujas transformações estruturais realizadas pelo Plano contribuíram para o desempenho favorável de determinadas contas da economia na década seguinte; e a visão de Prado (1994) apontando que se politicamente a visão de Lessa estava correta, a análise econômica desenvolvida por Castro e Souza não pode ser desconsiderada, pelos efeitos econômicos gerados. A despeito destes posicionamentos, o BNDES constituiu o principal agente financeiro do II PND. Logo, conhecer as ações e desempenho do Banco na execução deste Plano constitui importante inquietação acadêmica, dado que este configurou, ao lado do Plano de Metas, como um momento importante do planejamento estatal no Brasil.

Assim sendo, o presente trabalho propõe analisar a atuação do BNDES durante o II PND. Para tanto, encontra-se dividido em 4 seções, sendo que nesta $1^{\mathrm{a}}$ seção, aponta-se o seu propósito; na $2^{\text {a }}$. seção registra-se, de forma sintética, o padrão de financiamento brasileiro até o II PND; na $3^{\text {a }}$. seção, analisa-se a atuação do BNDES como agente financiador dos projetos do II PND a partir dos relatórios de atividades do Banco; e, por fim na $4^{\text {a }}$. seção, faz-se a conclusão.

\section{PADRÃo de FINANCIAMENTO NO BRASIL ATÉ O II PND: REGISTROS RELEVANTES}

No caminho da industrialização que percorreu a economia brasileira pós 1930 encontraram-se as primeiras iniciativas de intervenção do Estado. Dentro do novo marco industrializante criaram-se estruturas institucionais específicas para o desenvolvimento econômico no âmbito de uma formação, denominada de "ossatura material" (DRAIBE, 2004). O Estado, no curso dos acontecimentos, foi criando instrumentos mais eficientes de indução de políticas desenvolvimentistas industrializantes.

Entre 1951-1954, no segundo Governo Vargas, tentativas de endogeneizar o centro de decisão foram rechaçadas. Isto decorreu da principal debilidade da industrialização brasileira: a falta de um padrão endógeno de financiamento sustentado em um padrão de acumulação do capitalismo nacional. Diante da inadequação dos meios internos de financiamento frente às necessidades colocadas, recorreu-se ao financiamento externo público, orientado por instituições como o Banco de Exportação e Importação (Eximbank) e o Banco Interamericano de Reconstrução e Desenvolvimento (BIRD). Entretanto, a escolha por um governo de cunho nacionalista como o de Vargas constituiu um dos obstáculos para acessar os recursos vinculados aos projetos da CMBEU, inviabilizando o projeto nacional desenvolvimentista getulista (DRAIBE, 2004; AREND, 2009).

Entre 1955 e 1961, ao contrário do período anterior, em que havia escassez de recursos externos, principalmente em virtude do foco americano na reconstrução européia e japonesa, a economia mundial encontrava-se em uma fase de expansão. Além disso, ressaltase o caráter internacionalizante do processo de industrialização orientado pelo governo Juscelino Kubistchek (JK) (AREND, 2009). Favorecido por este processo o país passou a receber investimentos direto externos, que seriam fundamentais para o processo de 
industrialização (TEIXEIRA, 1983; AREND, 2009). Esses recursos foram oriundos da recuperação européia e expansão das suas empresas pelo mundo. Além do elemento internacional de financiamento, destaca-se o papel de políticas monetária e fiscal expansionista e dos recursos oficiais do BNDES voltados aos projetos de desenvolvimento deste período (LESSA, 1988).

Até 1960, o sistema financeiro nacional não dispunha de estrutura suficiente para atender as demandas que emergiam do processo de industrialização corrente. Sua estrutura era caracterizada por bancos comerciais que ofertavam fontes de financiamento de curto prazo. Para além dos bancos de desenvolvimento do Estado, tal qual o BNDES, a rede bancária privada não exercia qualquer função de desenvolvimento. Portanto, representava um entrave ao avanço do processo de industrialização pesada (BARKER, 1990).

Entre 1961 e 1966, ocorreu interrupção na trajetória do desenvolvimento. Neste período, figuraram os governos Jânio Quadros, João Goulart e o início do governo militar. Os dois primeiros sofreram os efeitos das políticas expansionistas, no campo fiscal e monetário de JK, resultando em uma deterioração da capacidade de financiamento e também da elevada inflação. As dificuldades econômicas e a instabilidade política resultaram na supressão do regime democrático, com o Golpe de Estado em março de 1964 (ABREU, 1990). O governo militar, em seu início, adotou ajuste econômico recessivo, via Plano de Ação Econômica do Governo (PAEG). Também, efetuaram-se reformas estruturantes como a fiscal, financeira, monetária, trabalhista e a previdenciária. A reforma fiscal possibilitou a recuperação da capacidade de investimento do Estado e a criação de captação compulsória, com o PIS e o PASEP, auxiliando a constituição do funding do BNDES (RESENDE, 1990).

Em complemento das reformas estabelecidas, foram implementadas duas leis no propósito de beneficiar os investimentos de mais longo prazo: 1) Lei de Reforma Bancária ( $\mathrm{n}^{\circ}$ 4.595, de 1964) que dividiu a tarefa de financiamento entre instituições comerciais, com crédito de curto prazo, e bancos de investimento privado e bancos de desenvolvimento públicos para crédito de médio e longo prazos; e, 2) Lei dos Mercados de Capitais ( $n^{\circ} 4.728$, de 1965) que criou incentivos para a expansão do mercado de capitais, por meio de incentivos para a abertura de capital e compra de ações (BARKER, 1990).

Cruz (1994) destaca que a estruturação do processo de industrialização, além da estrutura de mercado em oligopólio, exerce grande influência sobre as formas de financiamento. Para as empresas privadas que puxaram o crescimento da indústria, duas fontes de financiamento se destacaram: o autofinanciamento e o acesso a capitais externos. Também, destaca o papel de duas formas de financiamento não convencionais que marcaram o período: a política salarial vigente, onde os salários não acompanhavam o incremento da produtividade; e o financiamento inflacionário, sendo este um "mecanismo redistribuidor" em favor das indústrias (CRUZ, 1994: 68).

O setor público, por sua vez, e até mesmo em função do tipo de investimento que lhe coubera, não se baseou nas mesmas formas de financiamento observadas no setor privado (CRUZ, 1994). Os investimentos atribuídos ao setor público exigiam grandes volumes de financiamento e estes, na fase expansiva do Plano de Metas, foram atendidos pelo BNDES. Este foi orientado para diminuir a participação do financiamento ao setor público e aumentar os recursos para o setor privado, sobretudo nos anos 1970 (NARJBERG, 2002). Em complemento, passou-se adotar política de realismo tarifário, permitindo que empresas 
públicas praticassem preços em linha com a inflação, melhorando, assim, as condições de autofinanciamento (CRUZ, 1994).

Das reformas empreendidas a partir de 1964, resultou uma maior participação do setor financeiro nacional no processo de financiamento do dia-a-dia das empresas e também do financiamento de longo prazo, seja por meio de linhas de financiamento do governo ou através de empréstimos estrangeiros intermediados por bancos domésticos (BARKER, 1990). Entretanto, Cruz (1994) destaca que tais reformas não foram suficientes para a estruturação de instituições e instrumentos privados de financiamento de longo prazo. Assim, "o financiamento privado de longo prazo continuou a ser apontado como a grande lacuna do sistema financeiro nacional" (CRUZ, 1994: 65).

Entre 1967 e 1973, o Brasil viveu um período com taxas de crescimento expressivas, sendo até alvo da expressão "milagre". A média de crescimento do PIB anual neste período foi acima de $10 \%$. Este surto desenvolvimentista traz efeitos positivos para a economia brasileira, especialmente para a estrutura industrial. O financiamento deste salto para frente esteve a cargo dos empréstimos internacionais e também do Estado, através de títulos públicos, não mais de emissão monetária. Cabe destacar neste período a participação dos bancos públicos, Banco do Brasil e BNDES como agentes de financiamento. Além disso, a existência de alta liquidez internacional, proporcionada pelos capitais derivados do aumento dos preços do petróleo, os petrodólares, contribuíam para aumentar os recursos para financiar os investimentos públicos e privados. Neste período, o país apresentou os maiores avanços no processo de industrialização, chegando às portas de completar matriz produtiva o modelo fordista de produção (TAVARES; BELUZZO, 1998; LAGO, 1990).

Entretanto, o crescimento acelerado gerou elementos da crise econômica que se manifestaram no início dos anos 1970. Tavares e Belluzzo (1998) apontaram a ocorrência de crise de desproporcionalidade de crescimento entre os elos industriais: os setores de base e capitais avançam a frente dos seus demandantes. A análise feita por Singer (1976) evidenciou o esgotamento do processo de crescimento econômico em decorrência da crise de subconsumo no mercado. Ainda assim, o governo militar entendia que os projetos do II PND completaria a matriz industrial, reduziria a dependência externa e daria continuidade ao crescimento econômico do país.

\section{A ATUAÇÃO DO BNDES NO II PND - 1974-1979}

\subsection{BNDES e o II PND: análise pela ótica da sua diretoria}

A análise dos relatórios de atividades do BNDES nos anos de implementação do II PND no período de 1974 a 1979, permite-nos entender o alto grau de engajamento da instituição com a nova estratégia do governo brasileiro. A sua diretoria estava ciente de suas responsabilidades, o Banco iria assumir papel central no que se refere ao padrão de financiamento do plano. Esta instituição seria o principal agente interno responsável por disponibilizar créditos de longo prazo para os setores prioritários (BNDES, 1974).

Em 1974, o governo e o BNDES acreditavam que a nova configuração internacional traria efeitos negativos para o Brasil. A elevação do preço do petróleo acarretou uma alta generalizada de preços de outros insumos básicos da pauta de importação brasileira. Aliado a 
isso, observou-se também uma elevação do valor das importações de máquinas e equipamentos. Sendo assim, houve um aumento da inflação e uma piora no saldo do balanço de pagamentos. "Considerando esse novo quadro de dificuldades e atento ao objetivo maior de assegurar a continuidade do intenso processo de desenvolvimento nacional, o Governo Federal, em 1974, elaborou o II PND, que redefine as prioridades e metas de desenvolvimento do país" (BNDES, 1974, p.12).

Diante deste quadro geral e da concepção do Banco, de que ele seria o principal ator interno na alocação de investimentos, foi criado em 1974 o $1^{\circ}$ Plano Quinquenal de Ação. Os principais pontos desse plano podem ser analisados no Quadro 1. Observa-se que todos os programas tratados como prioridade pelo Banco são exatamente os principais objetivos do II PND. Como exemplo, podem-se citar os programas de insumos básicos e de equipamento básicos. O plano postulava uma inversão de prioridades no que se refere à dinâmica industrial. Se, durante o "milagre brasileiro", a indústria de bens de consumo duráveis era vista como principal ramo industrial e, consequentemente, como o setor que mais recebia investimentos, a partir de 1974 a atenção voltava-se para as indústrias de bens intermediários e de bens de capital.

A partir de 1964, o BNDES passou a criar maiores incentivos de apoio à indústria nacional privada. Sendo assim, um dos principais pontos do $1^{\circ}$ Plano de Ação do Banco era criar mecanismos no intuito de fortalecer esse setor. Nesse quadro inserem-se o Programa de Operações Conjuntas (POC) e o Fundo de Modernização e Reorganização das Indústrias (FMRI). Esses programas apoiaram, através de linhas de crédito abertas aos bancos de desenvolvimento, a expansão da capacidade produtiva, a dinamização de atividades econômicas selecionadas e o fortalecimento das empresas efetivamente nacionais (BNDES, 1974).

O desenvolvimento tecnológico também era visto como prioridade tanto para o II PND como para o BNDES. Neste sentido, o Fundo Tecnológico (FUNTEC), criado em 1964, foi aprimorado, ampliando qualitativamente a faixa de atuação desse instrumento. Tinha como finalidade prover o intercâmbio entre universidades e os institutos de pesquisa para que promovessem atividades voltadas ao desenvolvimento científico e tecnológico; aperfeiçoamento e a transferência de técnicas, processos e produtos; e, a absorção e utilização do processo tecnológico pela economia nacional (BNDES, 1974).

Outro ponto que evidencia o engajamento do Banco foi à criação de três subsidiárias: Mecânica Brasileira S.A (EMBRAMEC), Insumos Básicos S.A. (FIBASE) e Investimentos Brasileiros S.A. (IBRASA), além do fortalecimento da já existente FINAME. Essas quatro empresas mais o próprio Banco formariam o Sistema BNDES. Para seus dirigentes isso seria um salto em termos de atuação, dado a possibilidade de se alcançar todos os setores prioritários em todo o território nacional. Os relatórios de atividades citam também a importância dos agentes financeiros (bancos de investimentos e de desenvolvimento) para o desenvolvimento da estratégia do $1^{\circ}$ Plano de Ação. Com isso, permitiu colocar recursos à disposição das empresas industriais de qualquer ponto do país, seja qual fosse o porte (BNDES, 1975). 


\begin{tabular}{|c|c|}
\hline Programas & Objetivos \\
\hline Insumos básicos & $\begin{array}{l}\text { Aproveitar os recursos naturais disponíveis, assegurando o atendimento da } \\
\text { demanda de produtos básicos e contribuindo para aliviar a pauta de importações. } \\
\text { Seis subprogramas propostos: Siderurgia, Química e Petroquímica, Mineração, } \\
\text { Metalurgia de não Ferrosos, Fertilizantes, Celulose e Papel e Cimento. }\end{array}$ \\
\hline Equipamentos básicos & $\begin{array}{l}\text { Ampliar a fabricação de máquinas que produzem máquinas e de máquinas que } \\
\text { produzem produtos acabados. Suprir o mercado nacional de bens de } \\
\text { equipamentos e de capital, tecnologicamente complexos e não produzidos no país, } \\
\text { para permitir uma efetiva integração vertical dos setores industrializados e a } \\
\text { dinamização do processo de substituição de importações. }\end{array}$ \\
\hline $\begin{array}{l}\text { Outros programas de } \\
\text { fortalecimento da empresa } \\
\text { privada nacional }\end{array}$ & $\begin{array}{l}\text { Programas de Operações Conjuntas (POC), Fundo de Modernização e } \\
\text { Reorganização das Indústrias (FMRI). }\end{array}$ \\
\hline Infraestrutura & $\begin{array}{l}\text { Complementar os investimentos governamentais em transportes, armazenagem, } \\
\text { distribuição de energia e de gás, telecomunicações e infraestrutura de distritos } \\
\text { industriais, buscando eliminar obstáculos e estrangulamentos no processo de } \\
\text { aumento da produtividade global da economia. }\end{array}$ \\
\hline $\begin{array}{l}\text { Desenvolvimento } \\
\text { Tecnológico, Funtec }\end{array}$ & $\begin{array}{l}\text { Criar, adaptar e assimilar tecnologia por meio de incentivos às empresas e ao } \\
\text { intercâmbio entre estas e as universidades e institutos de pesquisa; } \\
\text { desenvolvimento científico e tecnológico, aperfeiçoamento e transferência de } \\
\text { técnicas, processos e produtos, e absorção e utilização do processo tecnológico } \\
\text { pela economia nacional. }\end{array}$ \\
\hline Consumo de Base & $\begin{array}{l}\text { Promover a produção, distribuição e comercialização de bens de consumo } \\
\text { essencial destinados principalmente aos segmentos da população de renda mais } \\
\text { baixa. Constituído de subprogramas que correspondem aos setores de produção e } \\
\text { distribuição de alimentos e medicamentos. }\end{array}$ \\
\hline Fomento Regional & $\begin{array}{l}\text { Apoiar a formação de novos polos de produção e contribuir para a expansão da } \\
\text { capacidade produtiva em microrregiões e setores de atividade de significativa } \\
\text { vocação local. }\end{array}$ \\
\hline Outros projetos & $\begin{array}{l}\text { Desenvolvimento de outros projetos - exemplos: Proterra e Programa Especial de } \\
\text { Apoio à Indústria Editorial (Prolivro). }\end{array}$ \\
\hline
\end{tabular}

Fonte: Tavares (2010, apud. Relatório de Atividades do BNDES, 1973 e 1974).

Elaborado pelo autor.

Para exercer a função de principal financiador interno do II PND, seria necessário elevar suas fontes de recursos, para tanto, em 1974, os recursos advindos do PIS e do PASEP foram transferidos para o BNDES. Tal medida demonstrou a confiança do governo em seus dirigentes, de acordo com o relatório de atividades de 1974 (BNDES, 1974, p.18): "considerando a importância e a relevância do papel representado pelo BNDES, como principal organismo de fomento às atividades econômicas, o Governo reforçou a capacidade de investir da instituição, canalizando para ela os recursos provindos do PIS e do PASEP”.

Com a base montada, o Banco continuou, em 1975, exercendo seu papel. O relatório de atividades de 1975 cita a boa atuação do BNDES, mesmo em um ano de crescimento mais moderado do país. Quatro fatores justificaram as ações do Banco: o empenho do governo em fortalecer a empresa privada nacional; a aplicação de investimentos nos setores estratégicos da economia, insumos básicos e bens de capital; a alta taxa de investimento da empresa privada nacional; e, a atuação eficiente dos agentes financeiros do Sistema BNDES (BNDES, 1975).

Em 1976, o Banco aprovou o maior número de operações até aquele momento da sua história. É importante ressaltar que nesse ano houve um reajustamento de seu Plano de Ação para o triênio seguinte. Entretanto, os setores prioritários continuavam a ser os setores 
dedicados ao incremento da produção interna de matérias primas e de máquinas e equipamentos, estreitamente acoplados ao fortalecimento da empresa privada nacional. Além disso, foi possível observar os primeiros resultados dos investimentos realizados desde 1974 (BNDES, 1976).

Foi também em 1976 que o BNDES criou dois instrumentos como forma de auxiliar suas subsidiárias na capitalização de empresas nacionais. O Programa Especial de Apoio à Capitalização da Empresa Privada Nacional (PROCAP), com abertura de linhas de crédito por meio de bancos de investimento, e o Programa de Financiamento a Acionistas (FINAC), destinado a financiar novos acionistas, pessoas físicas ou jurídicas, de empresas nacionais (BNDES, 1977).

No período que compreende 1974 a 1977, o Banco investiu maciçamente nos setores prioritários do II PND. Segundo dizeres do Relatório de Diretoria: “A importância crescente do BNDES no período 1974/77, pode ser ilustrada pela razão entre o saldo seus empréstimos e o saldo dos empréstimos de todo o sistema financeiro nacional: em 1977 essa razão atingiu 6,5\%, enquanto 1973 foi de apenas 2\%" (BNDES, 1977, p.22). Todavia, a partir de 1978, "o término efetivo e sucessivo dos principais empreendimentos em curso leva a constatação de que estão praticamente esgotadas as grandes oportunidades de investimento nessas duas áreas" (BNDES, 1978, p.5). Diante disso, seus dirigentes realizam um novo Plano de Ação para 1978/1981, cujas prioridades do Banco seriam outras a partir desse ano, seu papel como principal financiador do II PND acaba em 1978.

Nos termos do exposto observa-se que o BNDES elaborou Plano de Ação no propósito de auxiliar, como agente financeiro, na realização do II PND. Assim sendo: a) elevou o valor proveniente de suas fontes de recursos; b) criou três subsidiárias com finalidades específicas, além de fortalecer a já existente FINAME; e, c) elaborou mecanismos de apoio a empresa privada nacional e aprimoramento da FUNTEC, a fim de elevar o grau tecnológico da indústria brasileira.

No mesmo sentido, a leitura dos relatórios de atividades permite observar dois movimentos, sendo o primeiro dividido em dois sub-períodos. No primeiro período, entre 1974 a 1978, o Banco exerceu seu papel como agente interno de financiamento do II PND, sendo que, de 1974 a 1976, registrou-se elevado grau de aprovações e desembolsos para os setores prioritários; e, em 1977 e 1978 esse número é contido, entretanto, setores de insumos básicos e bens de capital continuaram sendo os setores que mais recebem financiamento. No segundo período, a partir de 1978, ocorreu reordenamento de atividades do Banco, sendo que a indústria de base não mais figurou como setor prioritário, para seus dirigentes, esta agência de financiamento cumpriu, de maneira bastante satisfatória, os objetivos que lhe foram entregues.

\subsection{BNDES e o II PND: análise dos dados}

Considerando que o BNDES foi moldado para ser o principal órgão interno no padrão de financiamento do II PND, é necessário observar como se comportaram os dados no período e responder as seguintes perguntas: Qual o grau da elevação do valor proveniente de fontes de recursos oriundas do BNDES? A empresa privada nacional realmente foi priorizada no que se refere aos desembolsos do BNDES? Quais foram os principais setores 
beneficiados? A estratégia de desconcentração industrial foi cumprida? Quais os principais programas de suas subsidiárias? Com essas análises realizadas pode-se concluir se o BNDES cumpriu ou não seu papel.

Com o propósito de se tornar o principal agente interno de financiamento do II PND, o BNDES contou com expansão de suas fontes de recursos, conforme pode ser observado na Tabela 1 e no Gráfico 1. Em 1979, os recursos do BNDES totalizaram R \$ 63,88 bilhões contra apenas R \$28,52 bilhões em 1974, o crescimento real médio anual das fontes de recursos do Banco no período 1974/1979 foi da ordem de 17,5\%.

Os recursos de geração interna podem ser obtidos através de retorno, incorporações ao capital de reservas e ressarcimento do Tesouro. As dotações e empréstimos do país estão divididos em dotação orçamentária, isto é, recursos do Tesouro Nacional, definidos no orçamento da União; reserva monetária, correspondendo basicamente ao Imposto sobre Operações Financeiras (IOF); PIS/PASEP, transferidos para o Banco em 1974; e outros. Recursos vinculados são aqueles depositados no BNDES com destinação especial e identificada a programas ou projetos. Por fim, estão os recursos captados fora do país, como recursos de mercado e recursos oficiais (PROCHNIK, 1995).

Tabela 1 - Fontes de recursos do BNDES, 1974/1979 (R\$ Bilhões de 2014)

\begin{tabular}{l|c|c|c|c|c|c}
\hline Fontes & $\mathbf{1 9 7 4}$ & $\mathbf{1 9 7 5}$ & $\mathbf{1 9 7 6}$ & $\mathbf{1 9 7 7}$ & $\mathbf{1 9 7 8}$ & $\mathbf{1 9 7 9}$ \\
\hline I - Geração Interna & $\mathbf{5 , 3 9}$ & $\mathbf{8 , 6 4}$ & $\mathbf{9 , 6 0}$ & $\mathbf{1 1 , 1 8}$ & $\mathbf{1 3 , 5 5}$ & $\mathbf{2 8 , 8 8}$ \\
\hline II - Dotações e Empréstimos no País & $\mathbf{2 1 , 2 3}$ & $\mathbf{3 5 , 0 0}$ & $\mathbf{3 1 , 7 2}$ & $\mathbf{3 4 , 3 4}$ & $\mathbf{3 2 , 4 3}$ & $\mathbf{2 4 , 0 4}$ \\
\hline 2.4 Dotação Orçamentária & 2,09 & 2,86 & 0,43 & 1,11 & 1,60 & 0,47 \\
\hline 2.5 Reserva Monetária & 13,20 & 9,97 & 7,49 & 9,10 & - & 1,90 \\
\hline 2.6 PIS/Pasep/FAT & 5,95 & 22,18 & 23,80 & 24,13 & 24,09 & 19,40 \\
\hline 2.9 Outros & - & - & - & - & 6,74 & 2,28 \\
\hline III - Vinculados Total & - & - & - & - & - & $\mathbf{1 , 1 4}$ \\
\hline IV - Recursos Externos & $\mathbf{1 , 9 0}$ & $\mathbf{4 , 4 8}$ & $\mathbf{2 , 5 2}$ & $\mathbf{5 , 7 7}$ & $\mathbf{7 , 3 1}$ & $\mathbf{9 , 8 2}$ \\
\hline 4.1 Rec. De Mercado (Moeda e Títulos) & 1,59 & 4,11 & 2,04 & 5,34 & 6,96 & 9,58 \\
\hline 4.2 Rec. Oficiais (AID e Financiamentos) & 0,30 & 0,36 & 0,46 & 0,43 & 0,35 & 0,24 \\
\hline Total & $\mathbf{2 8 , 5 2}$ & $\mathbf{4 8 , 1 2}$ & $\mathbf{4 3 , 8 4}$ & $\mathbf{5 1 , 2 9}$ & $\mathbf{5 3 , 3 0}$ & $\mathbf{6 3 , 8 8}$ \\
\hline Fon, & & & & &
\end{tabular}

Fonte: Adaptado de Prochnik (1995).

Obs: os valores desse artigo foram corrigidos pelo IGP-DI a preços de 2014, índice divulgado pela Fundação Getúlio Vargas.

Dentre os quatro tipos de fonte de recursos, as dotações e empréstimos no país, foram a de maior importância, (exceto em 1979). Tal constatação decorreu do fato, de que em 1974, as arrecadações do PIS/PASEP foram transferidas do Banco do Brasil para o BNDES, aumentando, portanto, seu raio de manobra. Já em 1975, os recursos do PIS/PASEP eram responsáveis por cerca de $46 \%$ das fontes de recursos do Banco. A geração interna de recursos também apresentou um importante crescimento, passando de R \$ 5,39 bilhões em 1974, para $\mathrm{R} \$ 28,88$ bilhões em 1979, apresentando um crescimento real médio anual de $39,9 \%$. Outro ponto a ser destacado foi à substancial redução dos recursos provenientes de reservas monetárias, cujo valor passou de R \$ 13,20 bilhões em 1974 para R \$ 1,9 bilhão em 1979. Esse movimento foi resultado do aperto monetário realizado pelo governo, sobretudo a partir de 1976, diante do recrudescimento do processo inflacionário e aumento do déficit público (REICHSTUL; COUTINHO, 1998). Sugestão: Poderia haver uma apresentação gráfica do que ocorre com a participação percentual em cada fonte ao longo do tempo. 


\section{Gráfico 1 - Evolução das fontes de recursos do BNDES, 1974/1979 (R\$ Bilhões de 2014)}

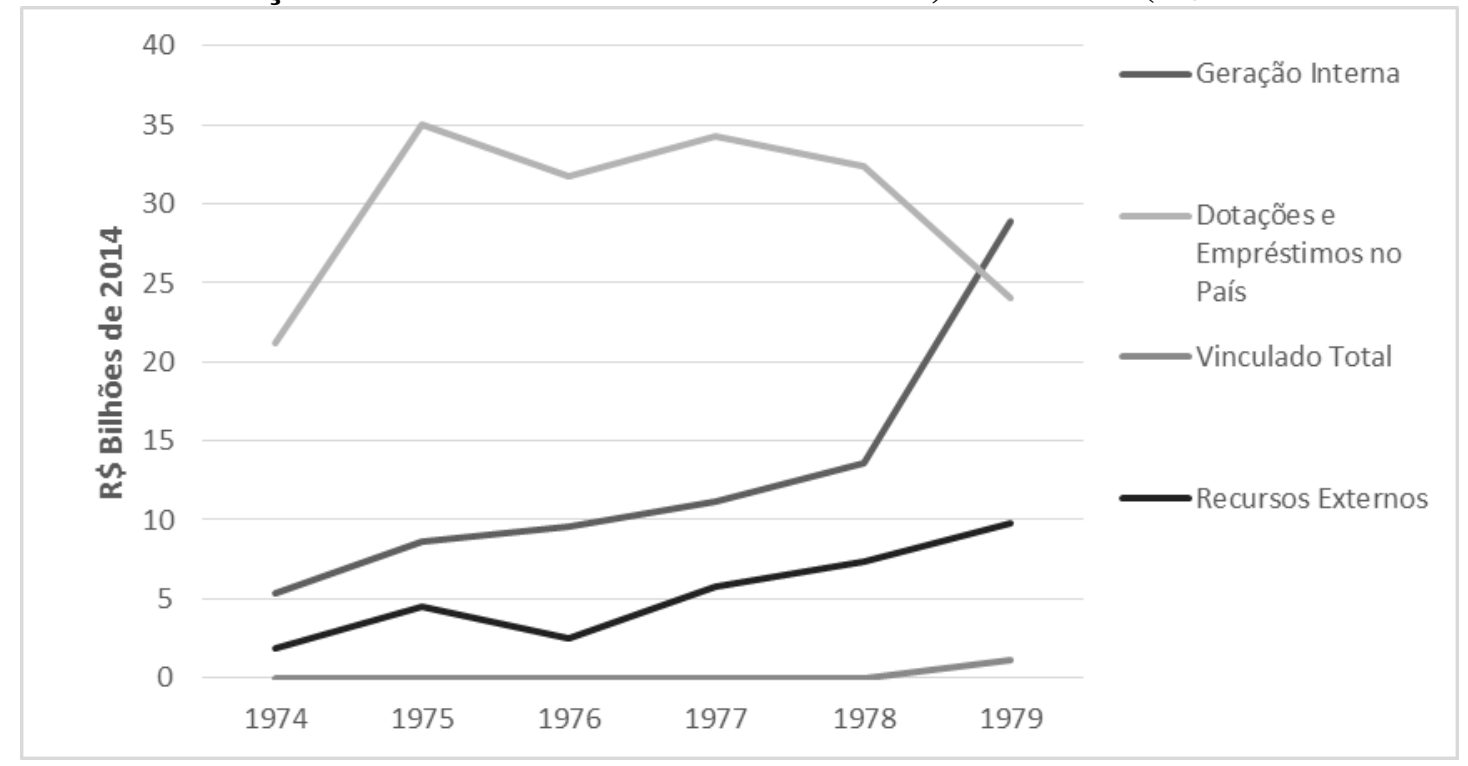

O objetivo da equipe econômica brasileira de capacitar o BNDES para fortalecer a empresa privada nacional também se concretizou na prática. O Gráfico 2 mostra a evolução da colaboração financeira do Sistema BNDES, aprovada em benefícios dos setores público e privado. Em 1974, do total de projetos aprovados pelo Banco, 34\% correspondiam ao setor público e $66 \%$ ao setor privado. Em contrapartida, em 1978, 90\% das aprovações totais eram voltadas ao setor privado, e apenas $10 \%$ ao setor público.

Gráfico 2 - Evolução da colaboração financeira do Sistema BNDES, aprovada em benefícios dos setores público e privado, 1974/1978 (R\$ Bilhões de 2014 e \%)

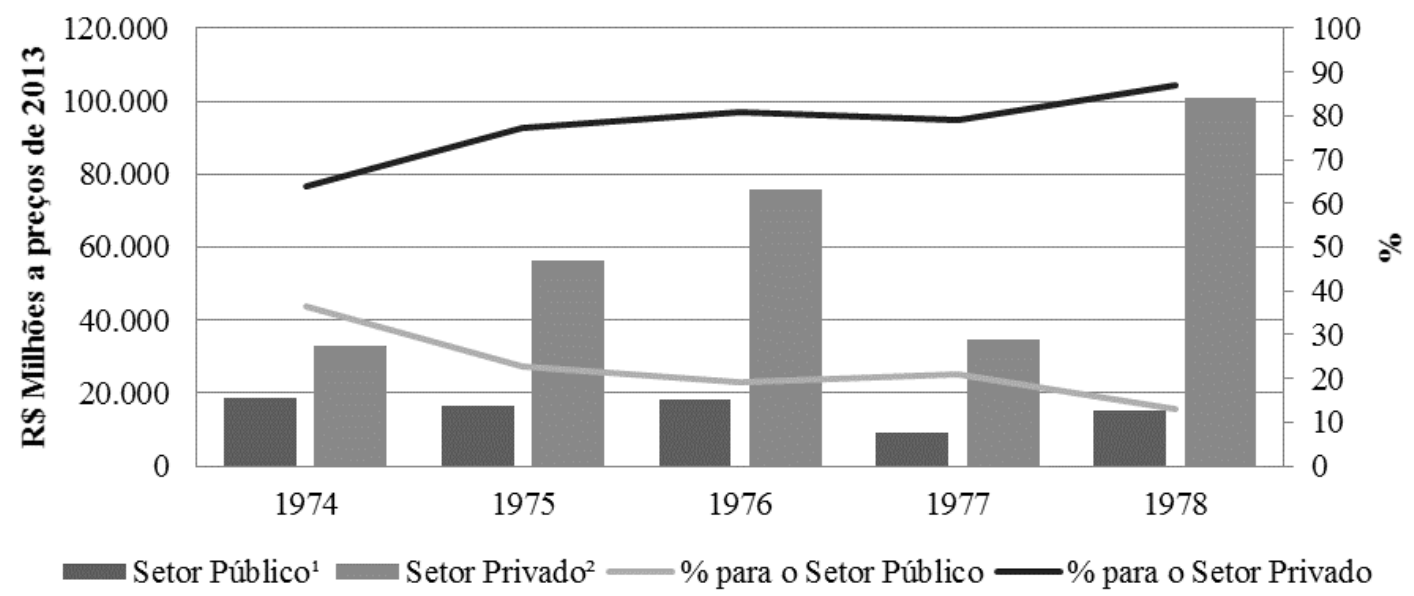

Fonte: Relatório de Atividades BNDES (1978)

${ }^{1}$ Inclui órgãos da administração pública direta e indireta, bem assim empresas com participação majoritária do governo.

${ }^{2}$ Inclui os totais das operações diretas e de repasses a agentes privados e oficiais dos diversos programas do BNDES, bem como o valor global das operações das subsidiárias.

Na definição de seu $1^{\circ}$ Plano Quinquenal de Ação, o BNDES criou mecanismos para auxiliar a indústria brasileira. O Programa de Operações Conjuntas (POC) e Fundo de 
Modernização e Reorganização Industrial (FMRI) constituíram exemplos claros deste propósito maior. Tais fontes auxiliaram, além das já citadas, o BNDES a cumprir função de instituição de financiamento da indústria privada nacional. Contribuiu para tanto, a orientação do governo para as empresas públicas buscarem financiamento de seus investimentos através do endividamento externo, liberando assim, recursos do BNDES para o financiamento das indústrias prioritárias do II PND. Esse movimento acabou por agravar o balanço de pagamentos brasileiro através do crescimento da dívida externa e do início da estatização da mesma.

A Tabela 2 mostra os desembolsos efetivados pelo sistema BNDES segundo os ramos e gêneros de atividades. A fim de atender os principais objetivos propostos no II PND e também no $1^{\circ}$ Plano Quinquenal de ação do Banco, os setores de insumos básicos e de equipamentos básicos foram altamente contemplados. Tais setores tiveram um crescimento real médio anual de recursos de $11,76 \%$ e $28,46 \%$, respectivamente no período 1974/1979. Do montante total desembolsado no período, 33,06\% foram para insumos básicos e 24,76\% para equipamentos básicos.

Entre 1974-1976, houve um grande aumento dos desembolsos efetivos do BNDES, passando de $\mathrm{R} \$ 52,98$ bilhões para $\mathrm{R} \$ 64,10$ bilhões, com um pico de $\mathrm{R} \$ 75,93$ bilhões em 1975. A partir de 1976, o crescimento passou a ser mais modesto. Isto decorreu da mudança de postura de governo nesse ano. O crescimento do nível inflacionário e os problemas no balanço de pagamentos levaram as Autoridades Monetárias a adotar medidas contracionistas, restringindo, portanto, o gasto da União e o financiamento do BNDES. Entretanto, ainda que menor, observou-se crescimento dos desembolsos. Os investimentos em andamento continuaram recebendo recursos. Como expressado anteriormente, os dirigentes do Banco acreditavam que a partir de 1978 os investimentos estariam completos, isso pode ser comprovado, dado que em 1979 ocorreu uma diminuição do valor desembolsado, quando comparado com o ano anterior.

Do valor total desembolsado pelo sistema BNDES no período 1974/1979 para o setor de insumos básicos, 46,97\% foram destinados para a siderurgia, 24,66\% para química e petroquímica e $10 \%$ para celulose e papel, esses foram os três principais setores de insumos básicos contemplados pelos desembolsos do BNDES. Segundo BNDES (1978), os recursos concedidos possibilitaram a produção de aço no Brasil atingir 12,1 milhões de toneladas em 1978, contra 7,5 milhões, em 1974. Assim como, o setor de celulose e papel, com unidades produtivas em várias regiões do país, em face dos investimentos realizados, passou a operar com elevada capacidade de produção, como a registrada em 1978, de 2,3 milhões de toneladas/ano. 
Tabela 2 - Desembolsos efetivados do Sistema BNDES segundo os gêneros e ramos de atividades, 1974/1979 (R\$ Bilhões de 2014)

\begin{tabular}{l|c|c|c|c|c|c}
\hline Setores & $\mathbf{1 9 7 4}$ & $\mathbf{1 9 7 5}$ & $\mathbf{1 9 7 6}$ & $\mathbf{1 9 7 7}$ & $\mathbf{1 9 7 8}$ & $\mathbf{1 9 7 9}$ \\
\hline Insumos Básicos & $\mathbf{1 9 , 4 2}$ & $\mathbf{3 6 , 8 0}$ & $\mathbf{2 8 , 2 2}$ & $\mathbf{3 1 , 9 5}$ & $\mathbf{3 6 , 5 9}$ & $\mathbf{2 8 , 3 3}$ \\
\hline Mineração & 0,31 & 0,56 & 0,63 & 1,60 & 1,36 & 0,41 \\
\hline Siderurgia & 13,42 & 18,86 & 10,43 & 12,14 & 16,15 & 14,16 \\
\hline Metalurgia de não ferrosos & 0,24 & 0,68 & 0,89 & 1,97 & 3,74 & 3,35 \\
\hline Química e Petroquímica & 3,32 & 7,09 & 9,18 & 9,77 & 8,93 & 6,42 \\
\hline Fertilizantes & 0,33 & 2,15 & 1,65 & 0,82 & 2,32 & 1,61 \\
\hline Celulose e Papel & 0,17 & 3,20 & 4,75 & 5,07 & 3,07 & 1,88 \\
\hline Cimento & 1,63 & 4,26 & 0,68 & 0,58 & 1,02 & 0,51 \\
\hline Equipamentos Básicos & $\mathbf{2 , 2 7}$ & $\mathbf{3 , 2 1}$ & $\mathbf{5 , 8 1}$ & $\mathbf{4 , 1 3}$ & $\mathbf{1 , 8 8}$ & $\mathbf{1 , 5 0}$ \\
\hline Outros Programas & $\mathbf{3 1 , 3 1}$ & $\mathbf{3 5 , 9 4}$ & $\mathbf{3 0 , 1 1}$ & $\mathbf{2 7 , 3 1}$ & $\mathbf{2 5 , 1 7}$ & $\mathbf{2 8 , 5 3}$ \\
\hline POC & 9,79 & 12,42 & 13,85 & 12,83 & 14,26 & 18,07 \\
\hline Pequena e média empresa & 9,65 & 11,84 & 10,89 & 8,08 & 4,37 & 5,34 \\
\hline Fomento Regional & 0,14 & 0,58 & 1,21 & 2,32 & 0,99 & 0,24 \\
\hline Fortalecimento de Agentes & - & - & 1,75 & 0,24 & 0,58 & 1,21 \\
\hline FINAC & - & - & - & 2,21 & 8,33 & 11,28 \\
\hline Modernização de empresas & 6,48 & 6,72 & 3,40 & 2,38 & 2,58 & 0,08 \\
\hline Infraestrutura & 7,22 & 11,06 & 7,20 & 5,59 & 5,36 & 5,04 \\
\hline Ferrovias & 3,54 & 2,76 & 1,85 & 2,13 & 1,93 & 1,71 \\
\hline Rodovias & 1,27 & 1,31 & 0,86 & 0,44 & 0,42 & 0,31 \\
\hline Outros setores & 2,41 & 7,00 & 4,49 & 3,02 & 3,02 & 3,02 \\
\hline Desenvolvimento Tecnológico & 1,00 & 0,91 & 0,51 & 0,22 & 0,17 & 0,08 \\
\hline PROCAP & - & - & 1,53 & 3,74 & 2,11 & 4,29 \\
\hline Outros Projetos & 6,83 & 4,84 & 3,62 & 2,54 & 0,70 & 0,97 \\
\hline Total BNDES Ajustado & $\mathbf{5 2 , 9 8}$ & $\mathbf{7 5 , 9 3}$ & $\mathbf{6 4 , 1 0}$ & $\mathbf{6 3 , 3 9}$ & $\mathbf{6 3 , 6 5}$ & $\mathbf{5 8 , 3 8}$ \\
\hline Fonte: Adaptado de BNDES & & & &
\end{tabular}

Fonte: Adaptado de BNDES (1992).

Nota: Exclui repasses as subsidiárias.

O segmento de equipamentos básicos recebeu maior desembolso em 1975, no valor de $\mathrm{R} \$ 5,81$ bilhões. É importante observar, que esse ramo industrial também foi contemplado com investimentos da EMBRAMEC e da FINAME, através de participação societária, FINAC ou outros investimentos, em linha com o propósito do II PND de promoção deste subsegmento vinculado à indústria de bens de capital. Os demais programas foram contemplados com $47,14 \%$ do total desembolsado pelo sistema BNDES. Destes, $45,53 \%$ foram investidos em operações com agentes, $12,14 \%$ em modernização de empresas, $23,25 \%$ em infraestrutura, $1,62 \%$ em desenvolvimento tecnológico, 6,54\% na capitalização de empresas e 10,93\% em outros projetos (BNDES, 1992).

Outro ponto a ser ressaltado em referência ao II PND relaciona-se ao objetivo de promover a desconcentração indústria e maior integração nacional. Neste sentido, o plano procurava promover investimentos nas regiões Norte, Nordeste e Centro-Oeste. O governo criou programas regionais, dentre os quais o Programa de Desenvolvimento de Áreas Integradas do Nordeste (Polonordeste); Programa de Polos Agropecuários e Agrominerais da Amazônia (Polamazônia); e Programa Especial de Desenvolvimento do Centro Oeste (Polocentro). Sendo assim, o planejamento realizado para o objetivo de se fazer uma desconcentração industrial é incontestável (LESSA, 1988). O BNDES, por sua vez, traçou essa meta no $1^{\circ}$ Plano de Ação e realçou a importância de se alcançar esse objetivo em seus relatórios. O Gráfico 3 mostra os desembolsos efetivados pelo Sistema BNDES, segundo as regiões no período 1974/1978. 


\section{Gráfico 3 - Desembolsos efetivados pelo Sistema BNDES segundo as regiões, 1974/1978 (\%)}

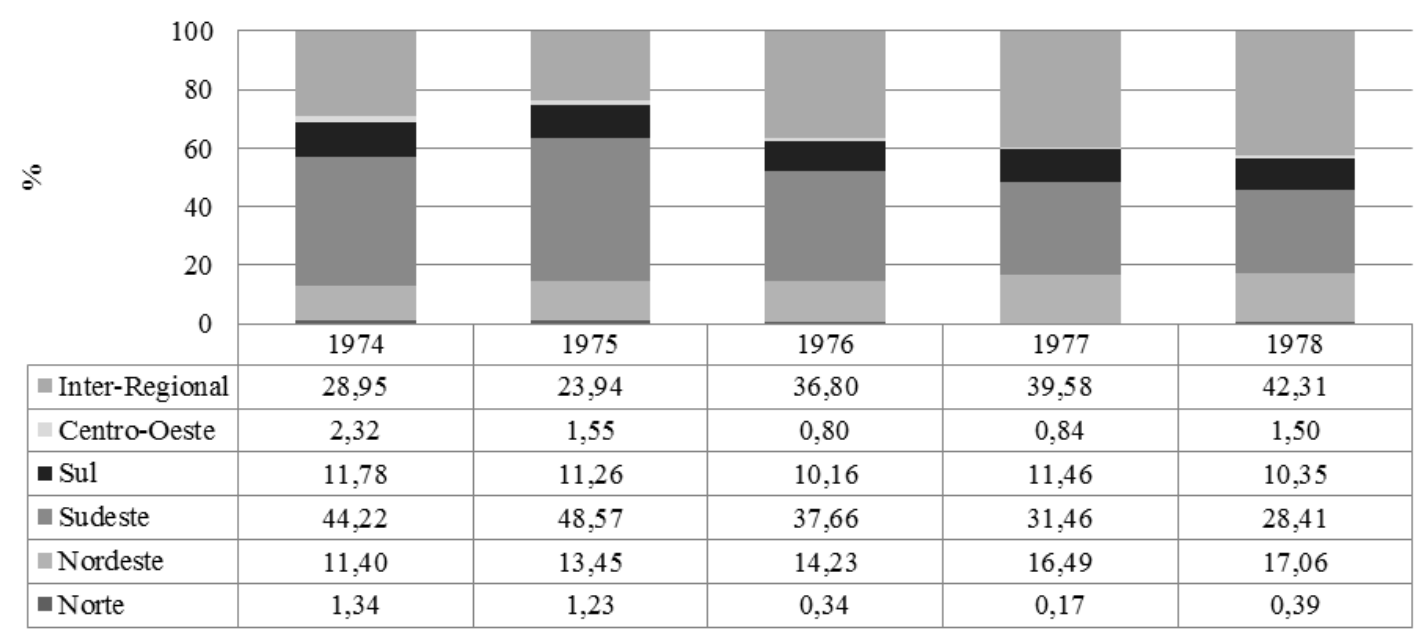

FONTE: Relatório de Atividades BNDES (1978).

Nota: No Inter-Regional estão computados os repasses as subsidiárias.

Nota-se que a região mais beneficiada foi a Sudeste, devido a grandes investimentos realizados, principalmente, no eixo Rio de Janeiro - São Paulo - Belo Horizonte, dado que essa região sempre foi a mais industrializada do país. Porém, o porcentual de desembolsos para região apresentou queda ao longo dos anos, em 1974, esta captava 44,22\% dos desembolsos do BNDES, em 1978 passou para apenas 28,41\%. Em contrapartida, a região Nordeste elevou a participação, de $11,40 \%$ para $17,06 \%$. Cabe salientar que a participação do investimento inter-regional mostrou trajetória de elevação. Em 1974, o valor da captação inter-regional representava 28,95\% dos desembolsos e, em 1979, elevou-se para 42,31\%.

De acordo com Tavares (2010), o BNDES alicerçou suas bases financeiras, principalmente através da expansão de suas fontes de recursos alimentadas pelo PIS/PASEP. Entretanto, em face dos altos investimentos sugeridos no intuito de alterar a dinâmica industrial brasileira, somente isso não seria necessário. Nesse sentido, criaram-se em 1974, como expressado anteriormente, as três subsidiárias do Banco, além de fortalecer a já existente FINAME. A criação dessas empresas fortaleceu a capitalização da empresa privada nacional.

A IBRASA tinha como principal objetivo capitalizar o setor industrial através de participação societária minoritária ou subscrição conversíveis em ações, para implantação ou expansão das empresas brasileiras. A FIBASE, voltada para o setor de insumos básicos, criava mecanismos financeiros mediante financiamentos e participações no intuito de viabilizar os empreendimentos da empresa privada. A EMBRAMEC montou esquemas financeiros através de financiamentos e participações como forma de auxiliar a produção de máquinas e equipamentos nacionais. A FINAME, por sua vez, seria responsável por financiar a comercialização de máquinas e equipamentos produzidos por empresas nacionais (ALVES PINTO, 1985). 
Tabela 3 - Valor das operações aprovadas e dos desembolsos efetivados pelo Sistema BNDES, 1974/1979 (R\$ Bilhões de 2014)

\begin{tabular}{c|c|c|c|c|c|c|c|c|c|c|c|c}
\hline \multirow{2}{*}{ Ano } & \multicolumn{2}{|c|}{ BNDES } & \multicolumn{2}{c|}{ FINAME } & \multicolumn{2}{c|}{ FIBASE } & \multicolumn{2}{c|}{ EMBRAMEC } & \multicolumn{2}{c|}{ IBRASA } & \multicolumn{2}{c}{ Sistema BNDES } \\
\cline { 2 - 14 } & A & D & A & D & A & D & A & D & A & D & A & D \\
\hline 1974 & 94,98 & 52,98 & 19,78 & 10,70 & 2,24 & 0,20 & 0,05 & 0,02 & 0,51 & 0,31 & 117,57 & 64,21 \\
\hline 1975 & 117,93 & 75,93 & 38,12 & 19,52 & 1,31 & 2,60 & 1,33 & 0,64 & 1,77 & 1,61 & 160,45 & 100,31 \\
\hline 1976 & 117,27 & 64,10 & 83,13 & 33,01 & 3,16 & 2,80 & 3,95 & 1,77 & 2,27 & 1,97 & 209,76 & 103,65 \\
\hline 1977 & 34,42 & 63,39 & 60,50 & 40,06 & 4,07 & 3,73 & 0,60 & 1,27 & 1,11 & 1,17 & 100,68 & 109,62 \\
\hline 1978 & 54,76 & 63,65 & 180,22 & 45,13 & 6,84 & 6,47 & 1,09 & 2,10 & 2,74 & 1,24 & 245,65 & 118,59 \\
\hline 1979 & 70,19 & 58,38 & 56,61 & 45,29 & 8,56 & 7,55 & 2,35 & 2,11 & 3,74 & 2,77 & 141,46 & 116,11 \\
\hline
\end{tabular}

Fonte: Relatório de atividades BNDES (1974, 1975, 1976, 1977, 1978, 1979)

Legenda: A: Operações Aprovadas; D: Desembolsos Efetivados.

A principal subsidiária, tanto no que se refere a aprovações e desembolsos, foi a FINAME, conforme a Tabela 3. Esta desembolsou no período 1974/1979 o valor de R\$ 193,72 bilhões, correspondendo 31,63\% do total desembolsado pelo Sistema BNDES. Em segundo lugar ficou a FIBASE com 3,82\%, seguido da IBRASA com 1,48\% e EMBRAMEC com 1,29\%. O próprio BNDES realizou desembolsos no valor de $\mathrm{R} \$ 378,43$ bilhões, correspondendo $61,78 \%$ do total. Tais números realçam a importância do Sistema BNDES para o padrão de financiamento do II PND. As quatro subsidiárias do Banco permitiram que o mesmo atuasse alinhado com as metas propostas pela estratégia de 1974, principalmente no que se refere a fortalecer a indústria privada nacional de insumos básicos e de bens de capital nacional.

Os principais desembolsos efetivados das subsidiárias, segundo os gêneros e ramos de atividade, podem ser observados na tabela 4. Nas três subsidiárias - FIBASE, EMBRAMEC e IBRASA - ocorreram maior desembolso na atividade de participação societária. A partir de 1977, o FINAC, programa criado em 1976, foi o gênero responsável por captar boa parte dos financiamentos do BNDES. Através desse programa o Banco contratava bancos privados de investimento, para através de abertura de crédito, facilitar a aquisição de ações de empresas privadas nacionais. Essas ações deveriam pertencer a empresas que operassem, principalmente, "no setor de máquinas e equipamentos, componente para a indústria elétrica, eletrônica e mecânica, siderurgia e metalurgia de não ferrosos, petroquímica e mineração" (ALVES PINTO, 1985, p.72).

A FINAME, diferentemente, operava por meio de três programas, a saber, o Programa de Médio Prazo, o de Longo Prazo e o Especial. O primeiro tinha por objetivo refinanciar as operações de máquinas e equipamentos fabricados no país, destinava-se às pequenas e médias empresas de controle nacional. O segundo contemplava faixas diferentes de financiamento, com prazos de amortização e de carência variável, de acordo com a destinação dos recursos mobilizados e do prazo de maturação do empreendimento, com taxa de juros preferenciais para investimentos no setor de bens de capital. Por fim, o terceiro objetivava refinanciar operações relativas a máquinas e equipamentos de fabricação nacional, produzidos sob encomenda (TAVARES, 2010).

Do total desembolsado pela FINAME, como pode ser observado na Tabela 4, 54,24\% do valor foi destinado para o programa especial, 30,33\% para o programa de longo prazo, $13,69 \%$ para o programa de pequena e média empresa ou o programa de médio prazo, e por fim, 1,72\% para outros programas da subsidiária. Para Tavares (2010, p.171), "a atuação das 
subsidiárias foi orientada no sentido de participar minoritariamente do capital de risco das empresas, podendo também praticar a tomada de debêntures em ações, bem como prestar garantias de subscrição".

Tabela 4 - Desembolsos efetivados das subsidiárias segundo os gêneros e ramos de atividades, 1974/1979 (R\$ Bilhões de 2014)

\begin{tabular}{l|c|c|c|c|c|c}
\hline Subsidiárias & $\mathbf{1 9 7 4}$ & $\mathbf{1 9 7 5}$ & $\mathbf{1 9 7 6}$ & $\mathbf{1 9 7 7}$ & $\mathbf{1 9 7 8}$ & $\mathbf{1 9 7 9}$ \\
\hline FIBASE & $\mathbf{0 , 2 0}$ & $\mathbf{2 , 6 0}$ & $\mathbf{2 , 8 0}$ & $\mathbf{3 , 7 3}$ & $\mathbf{6 , 4 7}$ & $\mathbf{7 , 5 5}$ \\
\hline Participação Societária & 0,14 & 2,54 & 2,74 & 2,91 & 4,82 & 7,09 \\
\hline Finac & - & - & - & 0,55 & 0,58 & 0,46 \\
\hline Outros Financiamentos & 0,05 & 0,06 & 0,06 & 0,27 & 1,07 & - \\
\hline EMBRAMEC & $\mathbf{0 , 0 2}$ & $\mathbf{0 , 6 4}$ & $\mathbf{1 , 7 7}$ & $\mathbf{1 , 2 7}$ & $\mathbf{2 , 1 0}$ & $\mathbf{2 , 1 1}$ \\
\hline Participação Societária & 0,02 & 0,64 & 1,77 & 1,02 & 1,43 & 1,00 \\
\hline Finac & - & - & - & 0,25 & 0,66 & 1,13 \\
\hline Outros Financiamentos & - & - & - & - & - & - \\
\hline IBRASA & $\mathbf{0 , 3 1}$ & $\mathbf{1 , 6 1}$ & $\mathbf{1 , 9 7}$ & $\mathbf{1 , 1 7}$ & $\mathbf{1 , 2 4}$ & $\mathbf{2 , 7 7}$ \\
\hline Participação Societária & 0,31 & 1,61 & 1,97 & 0,82 & 0,39 & 0,78 \\
\hline Finac & - & - & - & 0,38 & 0,77 & 2,01 \\
\hline Outros Financiamentos & - & - & - & - & - & - \\
\hline FINAME & $\mathbf{1 0 , 7 0}$ & $\mathbf{1 9 , 5 2}$ & $\mathbf{3 3 , 0 1}$ & $\mathbf{4 0 , 0 6}$ & $\mathbf{4 5 , 1 3}$ & $\mathbf{4 5 , 2 9}$ \\
\hline Programa Pequenas e médias empresas & 2,82 & 1,91 & 3,78 & 5,39 & 5,70 & 6,92 \\
\hline Programa de Longo Prazo & 1,50 & 9,97 & 14,08 & 12,73 & 10,45 & 10,04 \\
\hline Programa Especial & 3,46 & 7,23 & 15,18 & 21,94 & 28,96 & 28,32 \\
\hline Outros & 2,93 & 0,41 & - & - & - & - \\
\hline Total Subsidiárias & $\mathbf{1 1 , 2 3}$ & $\mathbf{2 4 , 3 8}$ & $\mathbf{3 9 , 5 6}$ & $\mathbf{4 6 , 2 3}$ & $\mathbf{5 4 , 9 4}$ & $\mathbf{5 7 , 7 4}$ \\
\hline
\end{tabular}

Fonte: Adaptado de BNDES (1992).

A estratégia do governo de tornar o BNDES o principal agente financiador do II PND não se mostrou apenas como uma retórica. Ao analisar os desembolsos efetivos realizados pelo sistema BNDES em relação à Formação Bruta de Capital Fixo (FBKF), como pode ser visto no Gráfico 4, ocorreu expansão da participação dos recursos concedidos pelo Banco no total dos investimentos do país. Em 1975, os desembolsos efetivos do BNDES corresponderam a 8,8\% da FBKF do Brasil, já em 1979 esse índice salta para 9,3\%. Apesar desse crescimento não ser tão alto, o II PND auxiliado pela atuação do BNDES permitiu que o nível de investimento não caísse, mesmo em um cenário nacional de reversão cíclica.

Gráfico 4 - Formação Bruta de Capital Fixo (FBKF) em participação do PIB e relação desembolsos do Sistema BNDES/FBKF - 1974/1979 (\%)

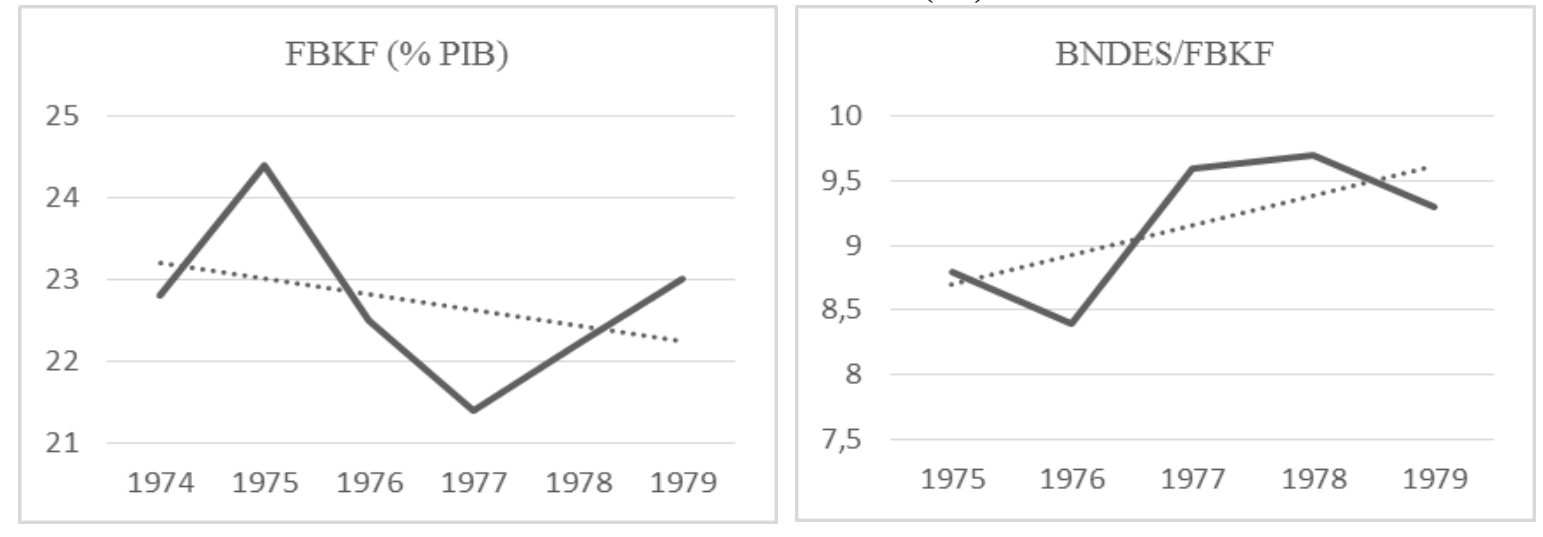

Fonte: Relatório de Atividades BNDES (1979) e A Ordem do Progresso (1990). 
Diante do exposto é possível responder à pergunta realizada no início dessa seção, isto é, o BNDES cumpriu seu papel em ser o principal financiador interno do II PND? Através das características apresentadas pelos dados responde-se de forma positiva ao cumprimento da função delegada. Entretanto, não foi possível atender totalmente a demanda proposta (? È preciso atender alguma coisa...) como pregam seus dirigentes nos relatórios de atividades. $\mathrm{O}$ baixo nível de investimento em tecnologia constitui um exemplo comprometedor da eficácia de atuação do Banco. Arend (2009), analisa a industrialização brasileira pela ótica tecnológica. Neste sentido, para o autor o II PND possui um duplo aspecto. Ele corroborou para que o país fosse inserido no paradigma metal-mecânico-químico. Entretanto, o plano não criou as bases necessárias para o Brasil se aproximar do novo paradigma tecnológico emergente nos países centrais, isto é, a revolução microeletrônica.(Como o(s) autor(es) chegaram a essa conclusão? Não é possível falar em tecnologia a partir dos dados apresentados? Verificar!) Mas, ao considerar a análise de forma geral e abrangente, o BNDES foi fortalecido e capacitado exercendo, portanto, o papel que lhe foi entregue.

Um primeiro aspecto que pode ser citado refere-se à elevação das fontes de recursos do Banco, sem isso a instituição não seria capaz de prover financiamentos suficientes para as metas do governo. A transferência da arrecadação do PIS/PASEP para seu passivo foi o ponto de inflexão fundamental para potencializar seus recursos. Além disso, com os financiamentos sendo desembolsados, a partir de 1974, ocorreu um aumento significativo de suas fontes internas, dado o retorno desses financiamentos mais juros.

No âmago do II PND, a estratégia de fortalecer a empresa privada nacional, fez com que o BNDES voltasse suas linhas de crédito quase que exclusivamente para o setor privado.

Analisando os principais setores beneficiados com os desembolsos efetivos do BNDES, é possível observar a convergência das ações do Banco com um dos propósitos do II PND. O núcleo central da estratégia de 1974 estava na indústria de insumos básicos e de bens de capitais, como forma de contornar os problemas referentes à nova situação internacional e nacional. Esses setores receberam os maiores desembolsos no período analisado. Apenas a partir de 1978, com o reordenamento de atividades do Banco esse cenário se modificou.

O fomento regional constituiu outro ponto de destaque do II PND. Melhor integração nacional através da desconcentração industrial era visto como essencial para o sucesso do plano. Quando se observa os desembolsos do BNDES, de acordo com as regiões, nota-se que a região Nordeste e os investimentos inter-regionais adquiriram papel mais relevante, quando comparado os anos anteriores. Apesar deste propósito, não se retirou do eixo Sul-Sudeste a dominância dos financiamentos, dada a base industrial encontrar-se fortemente concentrada neste eixo. 
Quadro 2 - Quadro síntese das principais ações desenvolvidas pelo BNDES, 1974/1979

\begin{tabular}{|c|c|}
\hline Principais Pontos & Síntese \\
\hline Fonte de recursos & $\begin{array}{l}\text { Somam-se as demais fontes já existentes do banco, os recursos advindos da } \\
\text { arrecadação do PIS/PASEP, aumentando o seu raio de manobra. O valor no início do } \\
\text { período foi de R\$ 27,07 bilhões em } 1974 \text { e no final, alcançou R } \$ 60,63 \mathrm{em} 1979 \text {. }\end{array}$ \\
\hline Setor público e privado & $\begin{array}{l}\text { O governo possuía a estratégia de financiar o setor privado através do BNDES e o } \\
\text { setor público através do endividamento externo. Isso é evidenciado na prática, em } \\
1979 \text {, quando } 90 \% \text { dos desembolsos do Banco destinaram-se para o setor privado. } \\
\text { Em 1974, esse número era em torno de } 70 \% \text {. }\end{array}$ \\
\hline Desembolsos e FBKF & $\begin{array}{l}\text { Ao observar a relação entre desembolsos do BNDES e a FBKF brasileira, nota-se a } \\
\text { elevação da participação do Banco no investimento do país. Esta participação passou } \\
\text { de } 8,8 \% \text { em } 1974 \text { para } 9,3 \% \text { em } 1979 \text {. }\end{array}$ \\
\hline Desembolsos Efetivos & $\begin{array}{l}\text { Os desembolsos voltaram-se para o programa de insumos básicos, equipamentos } \\
\text { básicos, operação com agentes, modernização de empresas, infraestrutura, } \\
\text { desenvolvimento tecnológico, capitalização de empresas, outros projetos, além de } \\
\text { repasses às subsidiárias. }\end{array}$ \\
\hline Fomento Regional & $\begin{array}{l}\text { A região Sudeste era a mais beneficiada com os desembolsos do Sistema BNDES, } \\
\text { porém a sua participação diminuiu. Em contrapartida, observou-se um aumento da } \\
\text { participação do Nordeste nos desembolsos totais e também dos investimentos inter- } \\
\text { regionais. }\end{array}$ \\
\hline Subsidiárias & $\begin{array}{l}\text { Três subsidiárias foram criadas a fim de auxiliar a atuação do banco: IBRASA, } \\
\text { FIBASE e EMBRAMEC. Além do fortalecimento da já existente FINAME. Essas } \\
\text { quatro subsidiárias mais o BNDES formavam o sistema BNDES. }\end{array}$ \\
\hline
\end{tabular}

Fonte: Elaborado pelo autor.

Pode-se, também, apontar a atuação das quatro subsidiárias. Neste sentido, constataram-se dois resultados favoráveis: $1^{\circ}$.) Cada subsidiária foi responsável por financiar investimentos dos setores produtivos prioritários no projeto do II PND, aprimorando o grau de alocação de recursos do BNDES; $2^{\circ}$.) O Banco se tornou sócio minoritário das empresas que captavam seus empréstimos, permitindo elevar o índice de capitalização das mesmas.

Por fim, cita-se a contribuição do BNDES na FBKF do Brasil. Os resultados apontaram o aumento da participação do financiamento do banco no computo geral dos investimentos do país. Logo, sem seus financiamentos, o investimento brasileiro provavelmente não teria alcançado níveis satisfatórios no período em análise.

Sendo assim, independente do debate existente em relação ao sucesso ou fracasso do II PND, o BNDES foi moldado para ser o principal agente interno no financiamento das metas propostas, neste sentido, exerceu seu papel de agente público de desenvolvimento (LESSA, 1982; CASTRO; SOUZA, 1985; PRADO, 1994). O Quadro 2, acima, traz uma síntese dos principais resultados da atuação do Banco.

\section{CONSIDERAÇÕES FINAIS}

A criação do BNDES, em 1952, vai totalmente ao encontro com a nova ideologia desenvolvimentista pró-industrialização inserida no Brasil, sobretudo a partir de 1930. Desta maneira, o país pode contar com uma instituição especializada em disponibilizar crédito de longo prazo durante todo o processo de criação e constituição do parque industrial brasileiro. É importante observar, que inicialmente o Banco tinha o objetivo de solucionar um dos principais pontos de estrangulamento da economia relacionados a questão infraestrutural. Com isso, suas principais linhas de financiamento se voltavam para esse setor no período de sua criação. Posteriormente, o BNDES, ao longo do tempo, constituiu-se no banco 
estruturante da economia brasileira, financiando a implantação de vários setores industriais, desde indústrias tradicionais - têxtil, alimentos, etc. - indústrias intermediárias - insumos básicos - e indústrias dinâmicas - máquinas e equipamentos, eletrônicos, química, etc.

O BNDES se constituiu no principal agente do padrão de financiamento doméstico do II PND. Plano este, voltado em consolidar as indústrias de intermediários e de bens de capital, e expandir os serviços infraestruturais - energia, transportes e comunicações - do país, no período de 1974-1979. Através deste, esperava-se completar a matriz industrial e manter a economia em trajetória de crescimento econômico, a despeito do quadro internacional não favorável a grandes inversões econômicas. O Banco foi capacitado pelas autoridades brasileiras para atender tais propósitos, e mostrou-se extremamente engajado nesse objetivo. A criação do $1^{\circ}$ Plano Quinquenal de Ação, em consonância com os objetivos estruturantes do II PND, constituiu referência, no atendimento da função desenvolvimentista requerida.

A partir dos dados analisados, tiram-se as seguintes conclusões. O Banco tornou-se o principal ator interno no padrão de financiamento do II PND, a partir do momento que aumentou o valor proveniente de suas fontes de recursos, principalmente, através da transferência da arrecadação do PIS/PASEP para seu passivo. O Banco voltou suas ações quase que exclusivamente para o setor privado, sendo que os principais setores beneficiados com linhas de financiamento, durante o período analisado foram tratados como prioridades pelo II PND. As quatro subsidiárias mostraram-se recursos indispensáveis para atuação do BNDES, desde o fomento para a capitalização das empresas para alavancarem os investimentos à concessão de crédito para compra de máquinas e equipamentos nacionais. Também, o Banco, neste período, elevou sua participação no montante de recursos destinados ao financiamento dos investimentos em relação ao PIB, em comparação com anos anteriores.

\section{REFERÊNCIAS BIBLIOGRÁFICAS}

ABREU, M. P. A Ordem do Progresso: cem anos de política econômica republicana 1889 1989. Rio de Janeiro: Campus, 1990.

ALVES PINTO, M. P. Governo Geisel: a crise de uma política econômica - o II Plano Nacional de Desenvolvimento, os pacotes econômicos e os pactos sociais. Dissertação (Mestrado em Economia) - Instituto de Economia, Unicamp, Campinas. 1985. 199 p.

AREND, M. 50 anos de industrialização do Brasil (1955-2005): uma análise evolucionária. Tese (Doutorado em Economia) - Programa de Pós-graduação em Economia, Universidade Federal do Rio Grande do Sul. 2009. 251 p.

BARKER, W. Os Bancos, a indústria e o Estado no Brasil. Revista de Economia Política (REP), São Paulo, v. 10, n. 2, abr. 1990.

BNDES. Relatório de Atividades. Rio de Janeiro: 1974, 1975, 1976, 1977, 1978, 1979 CASTRO, A. B.; SOUZA, F. E. A Economia Brasileira em Marcha Forçada. Rio de Janeiro: Paz e Terra, 1985.

CRUZ, P. R. D. C. Notas sobre o financiamento de longo prazo na economia brasileira do Após-Guerra. Economia \& Sociedade. Campinas, n. 3, dez. 1994. 
DRAIBE, S. Rumos e metamorfoses: Estado e industrialização no Brasil 1930/1960. Rio de Janeiro: Paz e Terra, 2004.

LAGO, L. C. L. A Retomada do Crescimento e as Distorções do "Milagre": 1967-1973. In: ABREU, M. P. (Org.). A Ordem do Progresso: cem anos de política econômica republicana 1889 - 1989. Rio de Janeiro: Campus, 1990. p. 233-294 .

LESSA, C. A Estratégia de Desenvolvimento, 1974/76: Sonho e Fracasso. Brasília: FUNCEP, 1988.

NARJBERG, S. Transformação do BNDES em financiador do Setor Privado Nacional. In: MONTEIRO FILHA, D. C.; MODENESI, R. L. (Org.). BNDES um banco de ideias: 50 anos refletindo o Brasil. Rio de Janeiro: BNDES, 2002. P. 345-354. Disponível em: $<$ http://www.bndes.gov.br/SiteBNDES/export/sites/default/bndes_pt/Galerias/Arquivos/conhe cimento/livro_ideias/livro-00.pdf>. Acesso em: 01 mar. 2015.

PRADO, S. R. R. Intervenção Estatal, Privatização e Fiscalidade: um estudo sobre a constituição e crise do setor produtivo estatal no Brasil e os processos de privatização a nível mundial. Tese (Doutorado em Economia) - Instituto de Economia, Unicamp, Campinas. 1994.

PROCHNIK, M. Fontes de Recursos do BNDES. Revista do BNDES, Rio de Janeiro, v. 2, n. 4, dez. 1995.

REICHSTUL, H. P.; COUTINHO, L. Investimento Estatal 1974-1980: Ciclo e Crise. In: Belluzzo, L. G. M.; COUTINHO, R. (Orgs.). Desenvolvimento capitalista no

Brasil: ensaios sobre a crise. Volume II. São Paulo: Brasiliense, 1998. p. 43-66.

RESENDE, A. L. Estabilização e reforma: 1964 - 1967. In: ABREU, M. P (Org.). A ordem do progresso: cem anos de política econômica republicana 1889-1989. Rio de Janeiro: Campus, 1990. p. 213-232.

SECRETARIA DO PLANEJAMENTO, PRESIDÊNCIA DA REPÚBLICA. II Plano Nacional de Desenvolvimento. São Paulo: Ed. Sugestões Literárias, 1975.

SINGER, P. A crise do milagre. São Paulo: Paz e Terra, 1976.

TAVARES, M. C. et al. O Papel do BNDES na Industrialização do Brasil: Os anos dourados do desenvolvimentismo, 1952-1980. Rio de Janeiro: Centro Celso Furtado, 2010. (Memórias do Desenvolvimento). Disponível em: <http://www.centrocelsofurtado.org.br/interna.php?ID_M=139\#.UB8OO02PVWU>. Acesso em: 01 mar. 2015.

TAVARES, M. C; Belluzzo, L. G. M. Notas Sobre o Processo de Industrialização Recente no Brasil. In: Belluzzo, L. G. M.; COUTINHO, R. (Orgs.). Desenvolvimento Capitalista no Brasil: Ensaios sobre a Crise. Volume I. São Paulo: Brasiliense, 1998. p. 139-160.

TEIXEIRA, A. O movimento da Industrialização nas Economias Capitalistas Centrais no Pós-Guerra. Dissertação (Mestrado em Economia Industrial) - Instituto de Economia, Universidade Federal do Rio de Janeiro, Rio de Janeiro. 1983. 
VELlOSO, J. P. R. O último trem para Paris. Rio de Janeiro: Nova Fronteira. 1986 